\title{
Effect of Desmodium intortum and black soldier fly larvae (Hermetia illucens) based meal on sensory and physicochemical properties of broiler chicken meat in Kenya
}

\author{
M.M. Mutisya ${ }^{1,2}$, S.B.S. Baleba ${ }^{1,3}$, J.N. Kinyuru ${ }^{4}$, C.M. Tanga ${ }^{1}$, M. Gicheha ${ }^{2}$, G. Hailu ${ }^{1}$, D. Salifu ${ }^{1}$, J. Egonyu ${ }^{1}$, \\ X. Cheseto ${ }^{1}$ and S. Niassy ${ }^{1 *}$ iD \\ ${ }^{1}$ International Centre of Insect Physiology and Ecology (icipe), P.O. Box 30772-00100, Nairobi, Kenya; ${ }^{2}$ Department of \\ Animal Science, Jomo Kenyatta University of Agriculture and Technology (JKUAT), P.O. Box 62000-00200, Nairobi, Kenya; \\ ${ }^{3}$ Max Planck Institute for Chemical Ecology, Department of Evolutionary Neuroethology, Hans-Knöll-Straße 8, 07745 Jena, \\ Germany; ${ }^{4}$ Department of Food Science and Technology, Jomo Kenyatta University of Agriculture and Technology (JKUAT), \\ P.O. Box 62000-00200, Nairobi, Kenya; sniassy@icipe.org
}

Received: 12 June 2021 / Accepted: 16 November 2021 (c) 2022 Wageningen Academic Publishers

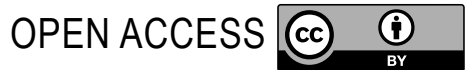

RESEARCH ARTICLE

\begin{abstract}
We evaluated the effect of dietary inclusion of different ratios of Desmodium intortum (DI) and black soldier fly larvae meal (BSFLM) on sensory traits and physicochemical qualities of broiler chicks meat. Three formulations: T1:75\%BSFL:25\%DI; T2:50\%BSFL:50DI, and T3:25BSFL:75\% DI as a protein source were tested. A conventional feed was used as the control diet. On day 42, the chickens were slaughtered, and thigh muscles were used for sensory and physicochemical evaluations. T1 was preferred for its flavour and tenderness, T2 for its juiciness and T3 for its colour, flavour, taste and overall acceptability scores. In terms of physical properties, all three types of meat had significantly lower moisture content and a higher water holding capacity than the control. T3 had the lowest moisture content, cooking loss and $\mathrm{pH}$, whereas the meat from control diet had the highest cooking loss and $\mathrm{pH}$. No significant differences were found in terms of meat lightness; however, meat from control diet showed the highest redness value, and T3 had the highest yellowness value. Dietary inclusion of DI-BSFL affected the fatty acid and cholesterol profiles of the meats. A holistic Principal Component Analysis indicated that the tested meats were distinct in their sensory and physicochemical properties. These variations in physicochemical properties may account for the difference in organoleptic perception, especially for T3. Further research should focus on feed modulation in relation to consumers' preference and potential health benefits.
\end{abstract}

Keywords: Desmodium, Hermetia illucens, insect-based feed, broiler chickens, meat quality

\section{Introduction}

Globally, modern poultry production is a fast-growing sector, mainly serving as an affordable source of animal protein, income and livelihood (Bett et al., 2012; Ravindran, 2013). Although significant technological advancements in genetic engineering and mass production of broiler birds have been achieved, access to quality poultry feed remains a major hindrance to the expansion of the sector (Min and Ahn, 2014; Mmereole, 2008; Ravindran, 2013). Conventional feed accounts for 70 to $80 \%$ of production cost, mainly due to the high cost of the protein component (Van der Poel et al., 2013). Conventional feeds which rely on soybean and fish meal for protein are mainly designed to enhance productivity and profitability. The overreliance on soybean and fish meal for feed is not tenable due to the competiting interest as human food, the high demand in water, and scarity of land. There is a need to innovate and identify sustainable feeds that will ensure optimal growth performance and carcass quality and improve the sensory, physicochemical attributes of the meat (Alex et al., 2017; Lichovníková et al., 2009).

In recent years, insects have been suggested as one of the most promising and sustainable alternatives to fish and soybean meals. The black soldier fly larva (BSFL; Hermetia 
illucens) is one of the insect species widely used globally as feed because of its rich nutritional profile. Studies have shown that black soldier fly larvae meal (BSFLM) can replace 25 to $100 \%$ of fish or soybean meals in broiler chicken, quails and barberry partridge feed and ensure optimal health status, satisfactory growth performance and overall meat quality (Cullere et al., 2016, 2017; Dabbou et al., 2018; Gariglio et al., 2019; Makkar et al., 2014; Secci et al., 2018). However, the amino acid profile of the BSFL is highly variable (Liland et al., 2017; Makkar et al., 2014). Recent studies demonstrated that the fat composition of BSFL might not be optimal for providing healthy meat for the modern consumer (Cullere et al., 2018). There is limited knowledge on consumer's opinion on the direct effect of BSFL replacement in poultry feed in terms of sensory attributes, confinement, colour, firmness, flavour and physicochemical meat quality. To a large extent, chicken producers and consumers attest to a link between diet composition and sensory and physicochemical attributes of chicken meat (Alex et al., 2017). Testimonies on the higher preference for local free-range chicken meat referred to as 'kienyeji, which fetches higher market prices, is mainly linked to its perceived superior taste (Omondi, 2017). The local chicken mainly acquires its nutrients through scavenging on insects and plant materials.

Furthermore, with the recent rising food consciousness among consumers, the healthfulness of broiler poultry meat and related products and meat appearance have become an important criterion for selection for purchase (Sow and Grongnet, 2010; Wideman et al., 2016). Meat attributes such as taste, tenderness, juiciness, drip loss, $\mathrm{pH}$, cooking loss, fat content and shelf life not only influence consumer perception but also processing functionality (sausage, minced meat) (Albrecht et al., 2019; Lonergan et al., 2004; Ondulla et al., 2019). To enhance such consumer-oriented attributes, the development of innovative and affordable feeds is crucial. Cullere et al. (2018) recommended supplementing feed with various essential amino acids to provide a diverse and balanced nutrient composition for the chicken. Plant-based proteins such as Desmodium intortum are suggested as a valuable substitute for poultry feed (Abdullah, 1974; Teguia and Beynen, 2005). D. intortum has an acceptable protein content, which can be as high as $24 \%$ (Heinritz et al., 2012), and contains an appropriate content of Methionine-Lysine and Threonine, which are the most limiting amino acids in broiler chicken feed. D. intortum has been proven to positively impact egg quality, specifically improved yolk colour and chicken performance (Mutisya et al., 2021; Teguia and Beynen, 2005). Studies on the inclusion of legumes and forages in broiler bird diets have also been shown to reduce cholesterol concentration in the animals' blood and meat, as well as improve feed conversion efficiency through improved digestion and metabolism (Jiang et al., 2012; Krauze and Grela, 2010; Ponte et al., 2005; Purwin et al., 2014).
D. intortum is widely recommended to smallholder farmers as a companion plant in push-pull farming system, to manage Striga weed, stemborers, and fall armyworm, which affect cereal production in Africa negatively. As a legume, $D$. intortum improves soil quality through nitrogen fixation, retain moisture and provides excellent fodder for livestock. We recently reported in previous studies that the combination of $D$. intortum and BSFL as feed ingredients in poultry diets improves animal performance and provide high returns to producers (Mutisya et al., 2021). The threelevel inclusion of $D$. intortum and BSFL consisted of a gradient of concentration of the two protein sources to evaluate their effect on sensory attributes and meat quality characteristics as these are critical drivers of consumer acceptance. However, the effect of such combinations on sensory attributes and meat quality characteristics, which are critical for consumers, have not been elucidated yet. Therefore, this study aimed to investigate the effects of BSFLM and D. intortum-based diets on broiler chicken meat's sensory and physicochemical properties.

\section{Materials and methods}

\section{Study site}

The poultry rearing was conducted at the International Centre of Insect Physiology and Ecology (icipe), Duduville Campus, Kasarani Sub- County, Nairobi County, Kenya (Latitude: $1.2219^{\circ} \mathrm{S}$; Longitude: $36.8967^{\circ} \mathrm{E}$ ). The general care and management of the animals followed accepted guidelines as described by the Federation of Animal Science Societies (FASS, 2010).

\section{Ethical approval}

The experimental design and all procedures conducted were based on animal welfare principles recommended by the National Research Council to avoid any discomfort or pain (McGlone, 2001). Sound animal husbandry practices were used to provide systems of care that permitted the chickens to grow to maturity and express their species-specific behaviour. Adequate veterinary care was provided to ensure proper animal health, and research assistants involved in the study were trained and motivated to achieve high-quality animal care throughout the experiment. A programme was implemented for disease prevention, surveillance, diagnosis and treatment (McGlone, 2001). Chickens were slowly acclimatised to handling by frequent exposure to kind and gentle handling by research personnel, starting at day one to ease handling at later stages of the study and increase feed efficiency and body weight gain (Gross and Siegel, 1983). Ethical approval for the study was provided by the Institutional Animal Care and Use Committee (IACUC) of the Kenya Agricultural and Livestock Research Organization (KALRO) - Veterinary Science Research Institute (VSRI); Approval Code No.: KALRO-VSRI/IACUC019/30082019. 


\section{Diet formulation}

The ingredients used in the feed formulation are shown in Table 1. The test diets were formulated according to the Kenya Bureau of Standards (KEBS) as guided by NRC (1994) specifications for broiler starter and finisher feeds. The isonitrogenous and isoenergetic diets $(3,000 \mathrm{kcal} / \mathrm{kg}$ ME, $220 \mathrm{~g}$ crude protein $/ \mathrm{kg}$ and 3,000 kcal ME, $180 \mathrm{~g}$ crude protein $/ \mathrm{kg}$ ) were prepared by replacing the fish meal content in the conventional diet (control diet) with BSFL and D. intortum. The following formulations were tested: $25 \%$ D. intortum $+75 \%$ BSFLM (T1), 50\% D. intortum +50\%BSFLM (T2) and $75 \%$ D. intortum $+25 \% \mathrm{BSFL}(\mathrm{T} 3)$. The three diets were chosen for their relatively high protein content and amino acid composition. The analysed nutrient and essential amino acid composition of the meals are presented in Table 1. For the finisher diets, the different mixtures containing all the required ingredients were pelletised at temps of $65{ }^{\circ} \mathrm{C}$ using a $50-80 \mathrm{~kg} / \mathrm{h}$ Pellet Machine manufactured and sold locally by Muharata Company Ltd. (Nairobi, Kenya). The pellet size was customised at $3 \mathrm{~mm}$ size for chickens, as indicated by the manufacturer. The dry matter, ash, crude protein, crude fibre, and ether extracts of the test diets fish meal, black soldier fly larvae meal and $D$. intortum meal were analysed according to the Association of Official Analytical Chemists (1990) methods. The amino acid content of the BSFLM and $D$. intortum was determined following the methods of 994.12 (AOAC 2002).

\section{Chicken rearing and management}

One hundred and twenty $(\mathrm{n}=120)$ mixed-sex 1 -d-old broiler chicks $\left(\mathrm{Cobb} 500^{\circ}\right)$ were sourced from Kenchic Ltd. hatchery in Thika, Kenya and reared for $42 \mathrm{~d}$ (i.e. 7 d adaptation phase and 35-d feeding phase). The chicks were placed in a common brooder room of $152.4 \times 182.88 \mathrm{~cm}$ for the first seven $\mathrm{d}$. Brooder temperatures were maintained at between $33-35{ }^{\circ} \mathrm{C}$ using light heating bulbs of 250 watts

Table 1. Feed composition for broiler starter and finisher diets ( $\mathrm{g} / \mathrm{kg}$ as fed). ${ }^{1}$

\begin{tabular}{|c|c|c|c|c|c|c|c|c|}
\hline & \multicolumn{4}{|c|}{ Broiler starter diets } & \multicolumn{4}{|c|}{ Broiler finisher diets } \\
\hline & Control & $\mathrm{T} 1$ & T2 & T3 & Control & $\mathrm{T} 1$ & $\mathrm{~T} 2$ & $\mathrm{~T} 3$ \\
\hline \multicolumn{9}{|l|}{ Ingredients } \\
\hline Maise germ & 528.8 & 527 & 540 & 550.2 & 550 & 526 & 534 & 576.5 \\
\hline Wheat pollard & 104.0 & 108 & 97.6 & 98.9 & 201.6 & 200.5 & 198.2 & 165.5 \\
\hline Corn oil & 24.6 & 16.3 & 11.4 & 4.0 & 27.2 & 22.1 & 15.2 & 5.4 \\
\hline Fish meal & 325.4 & 0 & 0 & 0 & 191.0 & 0 & 0 & 0 \\
\hline Desmodium & 0 & 82.65 & 165.3 & 247 & 0 & 55 & 110 & 165 \\
\hline Black soldier fly larvae meal & 0 & 247.95 & 165.3 & 82.7 & 0 & 165 & 110 & 55 \\
\hline Limestone & 10 & 10 & 10 & 10 & 22.6 & 22.6 & 22.6 & 22.6 \\
\hline Salt & 3.6 & 3.6 & 3.6 & 3.6 & 3.6 & 3.6 & 3.6 & 3.6 \\
\hline Di-calcium phosphate & 0.5 & 1.0 & 3.3 & 3.2 & 0.5 & 1.7 & 2.9 & 3.3 \\
\hline Broiler premix ${ }^{2}$ & 2.5 & 2.5 & 2.5 & 2.5 & 2.5 & 2.5 & 2.5 & 2.5 \\
\hline Mycotoxin binder & 0.1 & 1.0 & 1.0 & 1.0 & 1.0 & 1.0 & 1.0 & 1.0 \\
\hline Total & 1000 & 1000 & 1000 & 1000 & 1000 & 1000 & 1000 & 1000 \\
\hline \multicolumn{9}{|l|}{ Calculated values } \\
\hline Metabolisable energy (kcal/kg) & 2,997 & 3,018 & 3,021 & 3,037 & 3,052 & 3,053 & 3,059 & 3,100 \\
\hline Nitrogen free extracts (\%) & 43.9 & 44.1 & 42.0 & 42.1 & 45.2 & 44.6 & 43.5 & 34.0 \\
\hline \multicolumn{9}{|c|}{ Analysed nutrient content (\% dry matter basis) of experimental diets } \\
\hline Dry matter & 88.9 & 89.7 & 89.3 & 89.8 & 88.4 & 89.2 & 89.5 & 89.7 \\
\hline Crude protein & 22.1 & 23.1 & 22.8 & 21.4 & 21.5 & 22.5 & 22.0 & 21.0 \\
\hline Ether extracts & 6.8 & 7.3 & 7.4 & 8.1 & 8.4 & 7.9 & 8.1 & 9.2 \\
\hline Crude fibre & 3.4 & 5.7 & 7.1 & 7.6 & 3.1 & 5.9 & 7.3 & 7.8 \\
\hline Ash & 9.7 & 10.1 & 9.8 & 9.4 & 8.7 & 7.9 & 7.3 & 7.5 \\
\hline $\begin{array}{l}{ }^{1} \text { Control = conventional feed, } \mathrm{T} 1 \\
{ }^{2} \text { Broiler premix provided the follov } \\
1000 \text {,Vitamin B1 (Mg) } 500 \text {,Vitamin } \\
\text { Folic acid }(\mathrm{Mg}) 500 \text {, Biotin }(\mathrm{Mg}) 35 \\
\text { lodine }(\mathrm{Mg}) 600 \text {, Cobalt }(\mathrm{Mg}) 400 \text {, }\end{array}$ & $\begin{array}{l}\text { D. intortu } \\
\text { er kg of di } \\
\text { lg) } 2,500 \text {, } \\
\text { ine chloric }\end{array}$ & $\begin{array}{l}75 \% B S F L, \\
\text { Vitamin A(I } \\
\text { tamin B6 (M } \\
\text { (Mg) } 150,00 \\
M g) 125,00\end{array}$ & $\begin{array}{l}=50 \% D \\
6,250,00 \\
2,500, \mathrm{Vi} \\
\text { Iron }(\mathrm{Mg})\end{array}$ & $\begin{array}{l}\text { ortum+50 } \\
\text { itamin D3 } \\
\text { in B12 (Mg } \\
\text { 000, Copp }\end{array}$ & $\begin{array}{l}\mathrm{LM}, \mathrm{T} 3= \\
000,000, \\
\text { Pantotheni } \\
2,500, \mathrm{Zi}\end{array}$ & $\begin{array}{l}\text { D. intort } \\
\operatorname{nin} \mathrm{E}(\mathrm{I} . \mathrm{U} \\
\text { id }(\mathrm{Mg}) 6 \\
\mathrm{Mg}) 25,0\end{array}$ & $\begin{array}{l}25 \% \text { BSF } \\
5,000 \text {,Vitar } \\
\text { Nicotinic } \\
\text { Manganes }\end{array}$ & $\begin{array}{l}\mathrm{K}(\mathrm{Mg}) \\
\text { (Mg) } 15,000, \\
\text { (g) } 15,000,\end{array}$ \\
\hline
\end{tabular}


suspended at $45 \mathrm{~cm}$ height over the brooder to provide heat. These bulbs were supplemented with an automated thermostat heater model Xpelair ${ }^{\circ}$ (WH30, 3 KW Wall Heater; Peterborough, UK). Before the commencement of the experiment, all the chicks were fed on starter mash (conventional feed) purchased from Unga Feeds Limited (Nairobi, Kenya), the largest animal feeds manufacturer in East Africa. The chicks were fed at a rate of at least $125 \mathrm{~g}$ per $\mathrm{d}$ per chick. Feather sexing was done before the chicks were randomly distributed in 12 pens, each measuring $(1.5 \times 1.8 \times 1.5 \mathrm{~m})$ in a poultry house. Sexing was done to ensure that each pen contained 10 chicks ( 5 females and 5 males). The pens were separated using wooden blocks. A metallic mesh was used as the source of ventilation on the top side of the pens. Each treatment was replicated three times in a completely randomised design. The whole experiment comprised 120 chickens, with 30 chickens in each treatment, including the control.

Clean sawdust was obtained from a local carpentry workshop and spread on polythene papers on the floor of the cages at the height of $5 \mathrm{~cm}$ from the ground. After the $7 \mathrm{~d}$ brooding period, the chicks were weighed individually to obtain their initial weight before being introduced to starter diets of the BSFLM-DI formulations. The chickens were fed daily between 09:00 and 10:00. The feeding was ad libitum, but as a way of monitoring the bird's daily intake, twelve and a half kilograms of each feed treatment was measured daily using a weighing scale (Model; Camry EK 5055-005, manufactured by Zhongshan Camry manufacturer and Training Company limited, Zhongshan Guangdong, China, P.R.). The weight of feed consumed per cage was measured by difference (weight of feed in the bucket the following $d$ during feeding time subtracted from the weight of the feed in the bucket the previous day). Finisher diets containing BSFL and $D$. intortum were provided to the chicks after $21 \mathrm{~d}$. Clean drinking water was provided ad libitum using Kenpoly plastic feeders ( $10 \mathrm{l}$ capacity) per pen until the end of the rearing period when the chickens were isolated for slaughtering. The chickens were maintained at $28 \pm 1{ }^{\circ} \mathrm{C}$, relative humidity of $65 \pm 5 \%$ and a photoperiod of $12: 12$ (L:D) h light cycle. The temperature was gradually reduced by $2{ }^{\circ} \mathrm{C}$ every week up to week 4 . It was then maintained at $24{ }^{\circ} \mathrm{C}$. Waterproof universal serial bus temperature/ humidity data loggers were placed strategically inside the poultry house to monitor the internal conditions of the rearing facility. All the chickens were vaccinated against Newcastle disease on the fourteenth day.

\section{Slaughtering and carcass dissection}

The performance trial lasted $42 \mathrm{~d}$, after which the chickens were feed restricted overnight. Five chickens from each replicate were randomly selected for meat quality evaluation. The birds were sacrificed humanely by a professional using procedure reviewed and approved by the Institutional Animal Care and Use Committee (IACUC). The birds were first stunned electrically before slaughtering. The chickens were then scalded at $75{ }^{\circ} \mathrm{C}$ in a water bath for about 30 seconds before defeathering. The dressed chickens were later eviscerated to remove the internal organs, and the wings were removed by cutting anteriorly, severing at the humeo-scapular joint. The cuts were made through the rib head to the shoulder girdle, and the back was removed intact by pulling anteriorly. The internal organs such as the liver, gizzards, heart and spleen were weighed. The carcasses were packaged in Ziploc plastic bags measuring $28 \times 40 \mathrm{~cm}$ and frozen at $-20^{\circ} \mathrm{C}$ for sensory and physicochemical analysis.

\section{Sensory evaluation of the meat}

\section{Preparation of meat samples}

Chicken thigh muscles were used for all the treatments. The samples were then deskinned using sharp knives by tearing a part of the skin and then pulling it off. The deskinned whole thigh muscles samples were carefully wrapped in aluminium foils to avoid direct contact with the cooking water. They were then put in an aluminium cooking pot; water was added to cover the pieces and let to cook for 25 minutes. The cooking was done using an ordinary kitchen gas stove of the model (6 kg LPG meko; Allied East Africa, Limited Nairobi, Kenya). The heat-treated muscles were then removed from the water, unwrapped, and then cut crosswise into representative mouth-sized pieces.

Consumer testing was conducted at the Food Engineering Laboratory, Faculty of Food Science and Technology of the Jomo Kenyatta University of Agriculture and Technology (Nairobi, Kenya). A panel of 40 self-declared chicken eaters of mixed gender picked randomly were used for the evaluation. Five testing stations were set up at a distance of at least 2 metres apart. Chicken meat samples were placed on disposable white plastic plates partitioned into four sections (a section for every treatment). Each treatment was assigned a three-digit code indicating a specific sample: 325 - Treatment 1, 601 - Treatment 2, 225 - Treatment 3, 409 - Control. A glass of water was provided to panellists to rinse their mouth after tasting each treatment. The following attributes were assessed: meat colour, flavour (smell associated with cooked meat), taste (taste associated with cooked meat), tenderness (fibres perceived during mastication), juiciness (water perceived during mastication), and overall liking (overall satisfaction and desire to eat again). Panellists were guided throughout the process using a modified five-point hedonic scale $(1=$ dislike extremely, $3=$ neither like nor dislike, and $5=$ like extremely) (Damaziak et al., 2019). 


\section{Meat colour}

Broiler meat colour characteristics were determined using the CIELAB method, where the $\mathrm{L}^{*}, \mathrm{a}^{*}$ and $\mathrm{b}^{*}$ values were determined as illustrated by Qiao et al. (2001). The chicken thigh samples were defrosted overnight at $4{ }^{\circ} \mathrm{C}$, and the lean muscles were analysed using the CIE colourimeter (Minolta ${ }^{\oplus}$, Osaka, Japan). The $\mathrm{L}^{*}$, $\mathrm{a}^{*}$ and $\mathrm{b}^{*}$ values were recorded for each portion by taking the colour for three arbitrary places on the carcass. Finally, the recorded values were computed and analysed.

\section{Water holding capacity}

The meat water holding capacity was obtained from the breast meat samples. The samples were thawed overnight in a chiller at $4{ }^{\circ} \mathrm{C}$ using a modified filter paper press method. Samples weighing $0.3 \mathrm{~g}$ (initial weight) were obtained from the thawed meat samples and covered with a Whatman filter paper no.42 (Kobian Industries Ltd, Nairobi, Kenya). The samples were then pressed using a rheometer with the conditions $4 \mathrm{~kg}$ for 20 minutes. The final weight of the meat was then obtained. The percentage of free water was calculated using the following formula:

$\%$ Free water $=\frac{\text { Initial weight }- \text { Final weight }}{\text { Initial weight }} \times 100$

Water holding capacity $=100-\%$ Free water

\section{Cooking loss determination}

Cooking loss was determined by transferring frozen breast muscles into a $4{ }^{\circ} \mathrm{C}$ chiller to thaw overnight, from which samples weighing $60 \mathrm{~g}$ were carefully obtained, weighed and recorded as initial weight (W1). The samples were then put in plastic Ziplock bags, labelled and then placed in a digital electric water bath) which had been pre-heated to $80^{\circ} \mathrm{C}$ and cooked for 20 minutes. The cooked samples were then removed from the plastic bags and placed in an ice slurry for 2 minutes to cool down. The samples were then reweighed individually and recorded as W2 (cooked weight). The experiment was repeated 3 times, and the cooking loss was obtained using the following equation:

Cooking loss $(\%)=\frac{W 1-W 2}{W 1} \times 100$

\section{Moisture content}

Moisture content was determined using the air-oven drying method. Breast muscle samples stored at $-20^{\circ} \mathrm{C}$ in tightly closed containers were left to thaw overnight. They were then removed from the freezer $\left(\right.$ at $\left.4{ }^{\circ} \mathrm{C}\right)$ and placed on laboratory benches for 4 hours to warm up to room temperatures. Samples weighing $15 \mathrm{~g}$ (Iw) of each treatment diet (in triplicates) were weighed using a sensitive scale model and spread evenly on aluminium foil. The samples were then placed in an oven model pre-heated to $75{ }^{\circ} \mathrm{C}$ and left undisrupted for $48 \mathrm{~h}$. Using tongs, the samples were removed individually from the oven and placed in a desiccator for 30 minutes to cool at room temperatures. They were then reweighed and recorded as final weight $(\mathrm{FW})$. The following formula was used to calculate the percentage moisture.

$\%$ Moisture $=(F w-I w) \times 100$

\section{Determination of $\mathrm{pH}$}

The $\mathrm{pH}$ of the breast meat samples was determined using a portable digital $\mathrm{pH}$ meter model (Eutech Bench $\mathrm{pH}$ Meter, Trulab, Mumbai, India). Before each use, the meter was calibrated using a standard buffer solution of $\mathrm{pH}$ of 4.0 and 7.0 and then rinsed with distilled water after taking each sample. Breast meat samples were used for this analysis. The samples were first thawed overnight in a chiller at $4{ }^{\circ} \mathrm{C}$ and then deskinned. Readings were obtained by probing an electrode attached to the $\mathrm{pH}$ meter after $24 \mathrm{~h}$ at three random points on the chicken breast meat samples for $30 \mathrm{~s}$. The samples were measured in triplicates, and average $\mathrm{PH}$ values were calculated separately for every treatment and repeated after $24 \mathrm{~h}$ (Santos-Silva, 2001).

\section{Fatty acid composition}

$10 \mathrm{mg}$ of dry ground chicken meat samples were used. The compositions were analysed as fatty acid methyl esters as described by (Christie, 1993). $15 \mathrm{mg} / \mathrm{ml}$ of sodium methoxide was prepared in dry methanol, and $(500 \mu \mathrm{l})$ of the solution was added to the samples. The samples were vortexed for $1 \mathrm{~min}$, sonicated for $5 \mathrm{~min}$, and then incubated at $60{ }^{\circ} \mathrm{C}$ for $1 \mathrm{~h}$; these were thereafter quenched by adding $100 \mu \mathrm{l}$ deionised water followed by vortexing again for another $1 \mathrm{~min}$. The resulting methyl esters were extracted using gas chromatography (GC)-grade hexane $(1000 \mu \mathrm{l}$; Sigma-Aldrich, St. Louis, MO, USA) and centrifuged at $14,000 \mathrm{rpm}$ for $5 \mathrm{~min}$. The supernatant was dried over anhydrous $\mathrm{Na}_{2} \mathrm{SO}_{4}$ and analysed $(1.0 \mu \mathrm{l}$ ) by GC-MS on a $7890 \mathrm{~A}$ gas chromatograph linked to a $5975 \mathrm{C}$ mass selective detector (Agilent Technologies Inc., Santa Clara, CA, USA). The GC was fitted with a (5\%-phenyl)-methyl-polysiloxane (HP5 MS) low bleed capillary column $(30 \mathrm{~m} \times 0.25 \mathrm{~mm}$ i.d., $0.25 \mu \mathrm{m}$ : J\&W, Folsom, CA, USA). Helium at a flow rate of $1.25 \mathrm{ml} / \mathrm{min}$ served as the carrier gas. The oven temperature was programmed from $35^{\circ} \mathrm{C}(5 \mathrm{~min})$ with an increase rate of $10^{\circ} \mathrm{C} / \mathrm{min}$ to $285^{\circ} \mathrm{C}(20.4 \mathrm{~min})$. The mass selective detector was maintained at an ion source temperature of $230^{\circ} \mathrm{C}$ and a quadrupole temperature of $180^{\circ} \mathrm{C}$. Electron impact mass spectra were obtained at the acceleration energy of $70 \mathrm{eV}$. Fragment ions were analysed over $40-550 \mathrm{~m} / \mathrm{z}$ mass range in the full scan mode. The filament delay time was set at $3.3 \mathrm{~min}$. Serial dilutions of the authentic standard methyl octadecenoate $(0.2-125 \mathrm{ng} / \mu \mathrm{l})$ and hexanal $(1-280 \mathrm{ng} / \mu \mathrm{l})$ 
were analysed by GC-MS in full scan mode to generate a linear calibration curve (peak area vs concentration) which gave a coefficient of determinations $R^{2}=0.9997$ and 0.9997 for methyl octadecenoate and hexanal. These regression equations were used to evaluate the different fatty acids and volatile organic compounds, respectively. A HewlettPackard (HP Z220 SFF IntelXeon, Hewlett-Packard, Palo Alto, CA, USA) workstation equipped with ChemStation B.02.02.acquisition software (Hewlett-Packard) was used. The mass spectrum was generated for each peak using the Chemstation integrator set as follows: initial threshold $=5$, initial peak width $=0.1$, initial area reject $=1$, and shoulder detection $=o n$. The compounds were identified by comparing mass spectral data and retention times with authentic standards and reference spectra published by the library-MS databases: National Institute of Standards and Technology 05,08 , and 11 . The meat samples were analysed in triplicate, with each replicate collected from a different chicken.

\section{Cholesterol}

This was done using high-pressure liquid chromatography (HPLC) by a method described by (Almeida et al., 2006), which involves two main steps: saponification and cholesterol measurement. Saponification involved the addition of potassium chloride, $50 \%$ potassium hydroxide and $95 \%$ and $5 \%$ ethanol absolute and distilled water, respectively, to the sample. The sample was heated in a water bath for complete solubilisation at $60^{\circ} \mathrm{C}$ for $10 \mathrm{~min}$. This was followed by the addition of $5 \mathrm{ml}$ distilled icecold water, and the sample cooled in an ice bath. The nonsaponifiable fraction was extracted three times using $10 \mathrm{ml}$ of hexane. Aliquots of hexane extracts $(3 \mathrm{ml})$ were dried under a vacuum. The extract obtained from saponification was dissolved in $3 \mathrm{ml}$ of acetonitrile-isopropanol solution (70:30, v/v) and analysed with normal phase HPLC using unmodified silica gel as a stationary phase. The mobile phase consisted of acetonitrile and isopropanol $(70: 30, \mathrm{v} / \mathrm{v})$. The column used will be C18 ODS from Phenomenex ${ }^{\circledR}$ in the reverse phase. Cholesterol identification was done by co-chromatography and by comparing sample retention times with standard retention times. Quantification for each sample was achieved by using a standard curve for the standard solutions of different concentrations.

\section{Data analysis}

All analyses were conducted using the R environment for statistical computing (version 4.0.2) (R Core Team, 2020). For each sensory attribute (colour, flavour, juiciness, tenderness, taste, and overall acceptability), the chi-square test was used to compare the percentages of panellists across the three score levels (dislike extremely, neither like nor dislike and like extremely). Using two R packages called 'FactoMineR' (Lê et al. 2008) and 'Factoextra' (Kassambara and Mundt, 2020), we performed principal component analysis(PCA) was to visualise the different types of diet and the relationship existing among the different attributes. However, data from the physical property parameters of the different meat types were normally distributed (Shapiro-Wilk test: $P>0.05$ ), and their variances were similar (Bartlett's test: $P>0.05$ ). Therefore, in this study, we employed the analysis of variance (ANOVA) followed by the Student-Newman-Keuls (SNK) post-hoc tests (using the 'agricolae' R package (De Mendiburu, 2020)) to see whether these parameters were different across the different meats. Due to sample size, fatty acid data were analysed with non-parametric tests. The Kruskal-Wallis H test was used to assess differences in monounsaturated fatty acids (MUFA), saturated fatty acids (SFA) and cholesterol between treatments. All the significances were detected at $P<0.05$.

\section{Results}

\section{Sensory properties of the meat}

Results of the sensory properties showed that $\mathrm{T} 1$ was more preferred for its flavour (Figure 1B) and its tenderness (Figure 1D). Treatment T2 was preferred for its juiciness (Figure 1C), while T3 was preferred for its colour (Figure 1A), flavour (Figure 1B) and taste (Figure 1E). Consequently, T3 had the highest overall acceptability (Figure 1F). According to the proportion test, no significant differences were detected between treatments within the same category at $5 \%$. Overall, the sensory attributes were sampled adequately (Kaiser-Meyer-Olkin $>0.8$ ), and Bartlett's sphericity test revealed a significant positive correlation between the different attributes $(P<0.0001)$.

\section{Physicochemical properties of the meats}

The meat colour analysis results revealed that meats from the different treatments were not significantly different in their lightness $(P=0.692)$. However, significant differences were found in their redness and yellowness $(P<0.001 ; P<0.001)$. The control treatment recorded the highest value for redness, followed by T1, then T2, and T3 had the lowest value. T3 recorded the highest value for yellowness, followed by $\mathrm{T} 2$ and $\mathrm{T} 1$. The control had the lowest value for yellowness and was not significantly different from T1 (Table 2).

We found that moisture $\left(\mathrm{F}_{3,32}=13.2, P<0.0001\right)$, water holding capacity $\left(\mathrm{F}_{3,32}=6.13, P=0.002\right)$, cooking loss $\left(\mathrm{F}_{3,32}=29.73, P<0.0001\right)$, and $\mathrm{pH}\left(\mathrm{F}_{3,32}=20.23, P<0.0001\right)$ were significantly different across the different meat types. Control and T3 had respectively higher and lower moisture content than T1 and T2 (Figure 2A). The water holding capacity was significantly lower in control than T1, T2, and T3 (Figure 2B). The cooking loss was higher in control and significantly reduced in T1, T2 and T3, respectively (Figure 

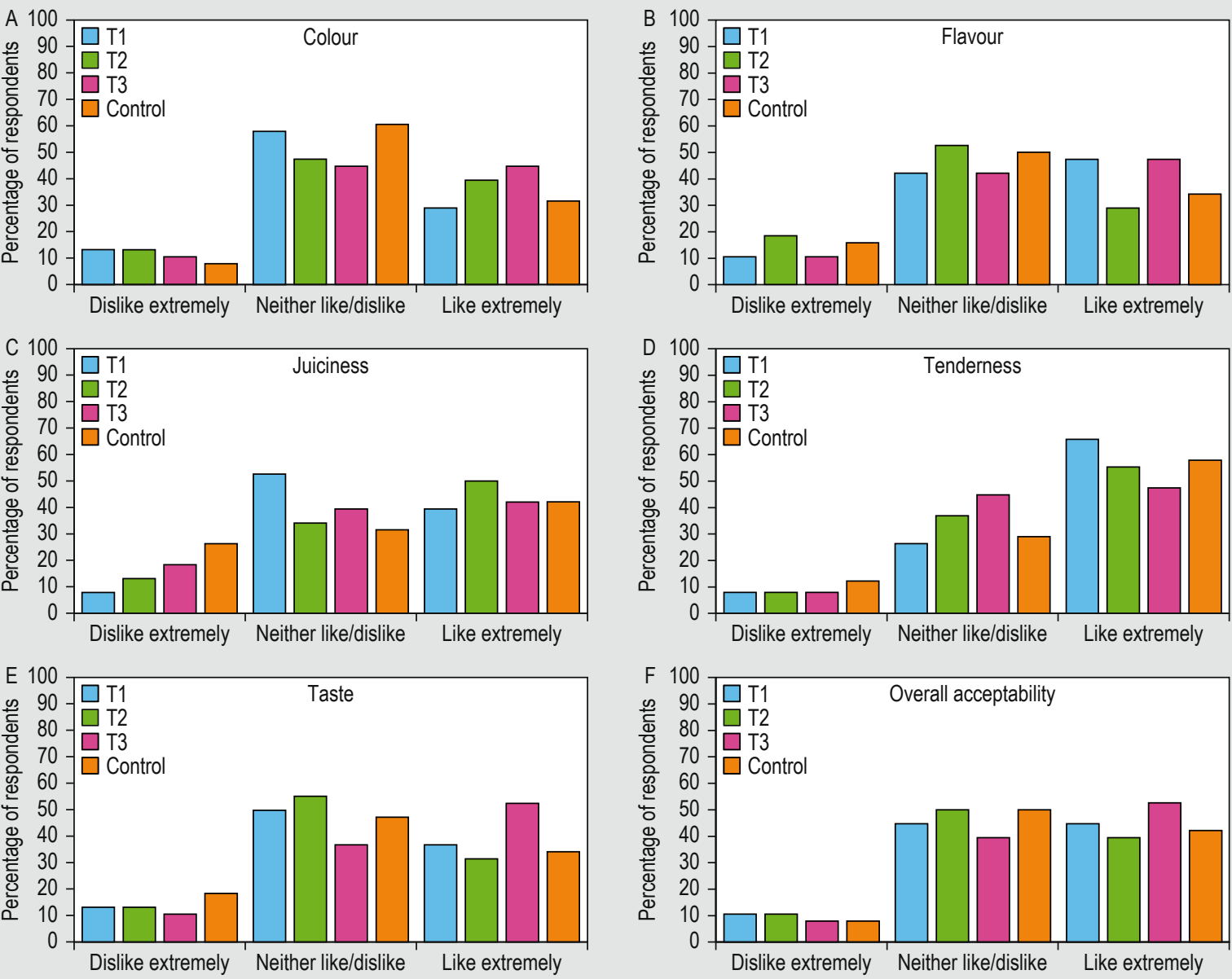

Figure 1. Percentage of respondence to each attribute score across the various type of diets. Control = conventional feed, $\mathrm{T} 1=$ $25 \%$ D. intortum+75\% BSFLM, T2 = 50\% D. intortum+50\% BSFLM, T3 = 75\% D. intortum+25\% BSFLM.

Table 2. Effect of black soldier fly larvae and Desmodium based diets on the meat colour of broiler chicken.

$\begin{array}{llll}\text { Treatment }^{1} & \mathbf{L} \text { (Lightness) } & \mathbf{a}^{*} \text { (Redness) } & \mathbf{b}^{*} \text { (yellowness) } \\ \text { Control } & 53.5 \pm 0.57 \mathrm{a} & 5.21 \pm 1.7 \mathrm{~d} & 4.53 \pm 0.1 \mathrm{a} \\ \text { T1 } & 53.6 \pm 0.1 \mathrm{a} & 4.93 \pm 1.6 \mathrm{C} & 5.16 \pm 0.4 \mathrm{a} \\ \text { T2 } & 53.3 \pm 0.17 \mathrm{a} & 4.42 \pm 1.5 \mathrm{~b} & 5.32 \pm 0.4 \mathrm{~b} \\ \text { T3 } & 53.5 \pm 0.23 \mathrm{a} & 4.13 \pm 1.4 \mathrm{a} & 7.53 \pm 0.4 \mathrm{C} \\ \text { P-value } & 0.692 & <0.001 & <0.001\end{array}$

\footnotetext{
${ }^{1}$ Control $=$ conventional feed, $\mathrm{T} 1=25 \% \mathrm{D}$. intortum $+75 \% \mathrm{BSFLM}, \mathrm{T} 2=50 \% \mathrm{D}$. intortum $+50 \% \mathrm{BSFLM}, \mathrm{T} 3=75 \% \mathrm{D}$. intortum+25\% BSFLM. Data is expressed as means $(\%) \pm$ standard deviation. Means with different letters within each column are significantly different at $P<0.05(\mathrm{n}=3)$. Change in colour $(\Delta \mathrm{E})$; Lightness $\left(L^{*}\right)$; red/green colour $\left(a^{*}\right)$; yellow/blue colour $\left(b^{*}\right)$.
}

2C). The $\mathrm{pH}$ was higher in control and lower in $\mathrm{T} 3$, whereas in $\mathrm{T} 1$ and $\mathrm{T} 2$, this parameter was similar (Figure 2D).

The fatty acid and cholesterol composition of the meat in the various treatments is presented in Table 3. Meat samples from $\mathrm{T} 1$ and $\mathrm{T} 2$ had the highest concentration of
MUFA, followed by control and lowest in T3. There were variations in terms of SFA whereby $\mathrm{T} 1$ and $\mathrm{T} 2$ recorded the highest values followed by control then T3. The cholesterol levels were higher in T1, T3, control followed by T2. However, in all these groups, no significant differences were detected at $5 \%$. 
A

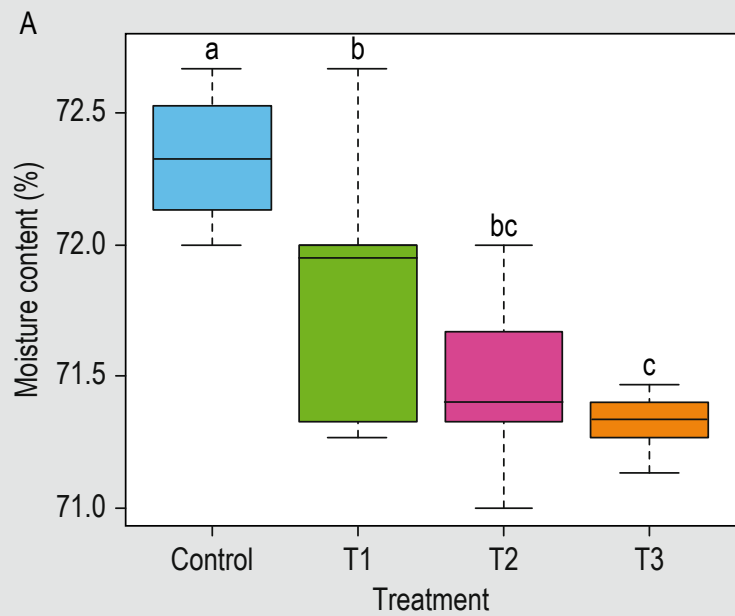

C

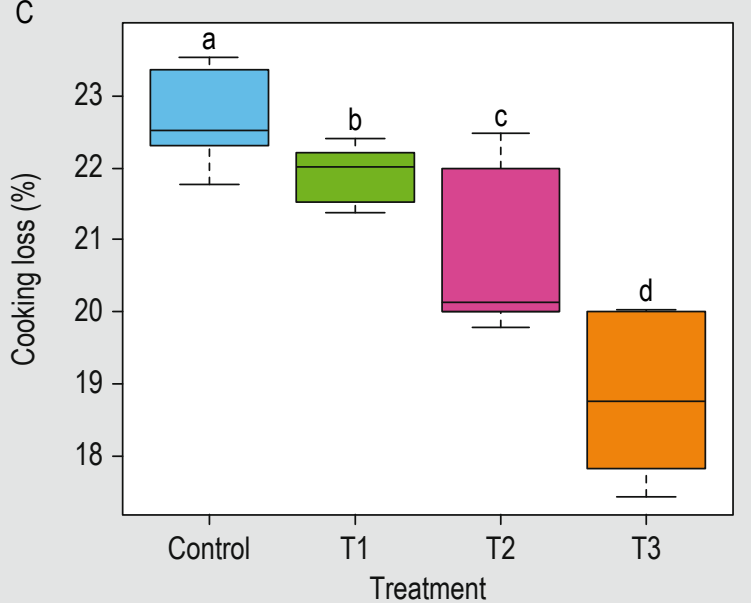

B

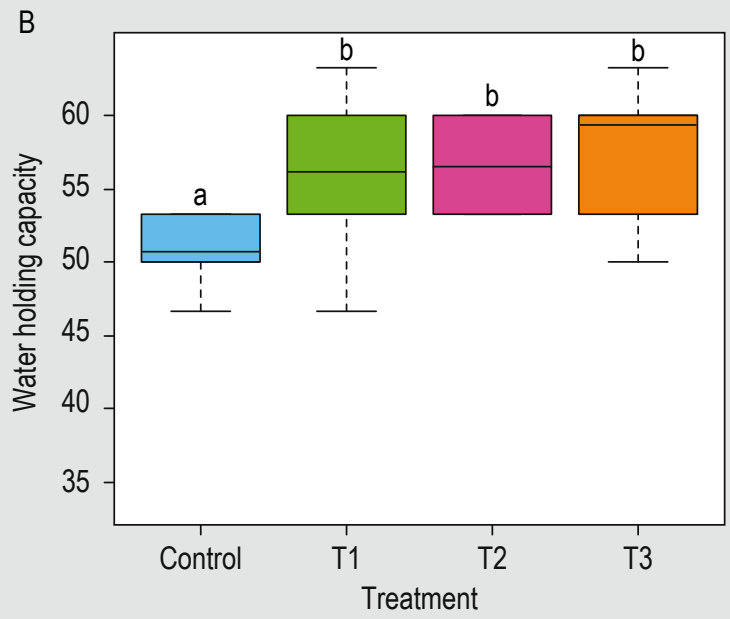

D

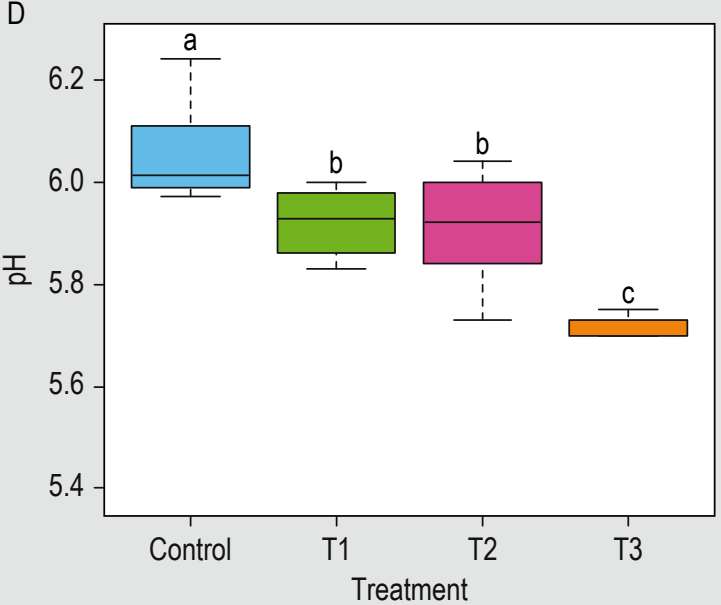

Figure 2. Boxplot illustrating the effect of black soldier fly larvae meal (BSFLM) and Desmodium intortum based diets on (A) moisture content, (B) water holding capacity, (C) cooking loss, and (D) pH, on broiler meat. The ends of boxplot whiskers represent the minimum and maximum of all the data. Control $=$ conventional feed, $\mathrm{T} 1=\mathbf{2 5} \% \mathrm{D}$. intortum+75\% BSFLM, $\mathrm{T} 2=\mathbf{5 0} \%$ D. intortum+50\% BSFLM, T3 $=75 \%$ D. intortum+25\% BSFLM. Boxes with different letters are significantly different based on the ANOVA followed by SNK post-hoc tests.

The principal component analysis biplot (Figure 3) obtained from the sensory and the physicochemical parameters data clustered the four meat types (control, T1, T2, and T3), illustrating the importance of these parameters in meat differentiation. The first two dimensions explained $56.2 \%$ of the total variation. Dimension 1 mainly was associated with fatty acids (e.g. butanoic, eicosanoic and dodecanoic acids) and accounted for $39.3 \%$ of the total variation. Dimension 2, which accounted for $16.9 \%$, was correlated with redness, cooking loss, moisture and $\mathrm{pH}$.

\section{Discussion}

The combination of $D$. intortum and BSFLM as a protein source in formulating broiler chicken feeds affects various sensory attributes of the meat. Treatment T3, which has the highest $D$. intortum rate, had the highest overall acceptability. Although few studies have been conducted on the sensory effects of adding legume forages such as
$D$. intortum in combination with BSFL in broiler diets, the increased sensory appeal of the D. intortum-BSFLM based diets is unique and corroborates previous studies (Cullere et al., 2017; Ponte et al., 2005; Secci et al., 2018). In addition, the combination of taste, odour, juiciness, and mouthfeel affects the meat's sensory properties; this confirms the reduced moisture content and higher water holding capacity of chickens fed with $D$. intortum-BSFLM meat samples (Zhao et al., 2013).

In our study, the physical attributes of meat from the various treatments differed. An increase in D. intortum-BSFLM mixture has a significant effect on the physical attributes of the meat, particularly the moisture retention, $\mathrm{pH}$ and water holding capacity confirming previous findings (Reicks et al., 2011). The $\mathrm{pH}$ value is an indicator of change in glycogen decomposition rate into lactic acid in the muscles. The rapid decline of $\mathrm{pH}$ also affects the colour and the water holding capacity. This could be ascribed to the rapid growth and 
Table 3. Effect of black soldier fly larvae (BSFL) and $D$. intortum based diets on the fatty acids profile ( $\mathrm{mg} / \mathrm{kg}$ ) in broiler chicken breast meat. ${ }^{1,2}$

\begin{tabular}{|c|c|c|c|c|c|c|c|}
\hline Type of fatty acid ${ }^{3}$ & $\mathrm{tR}(\min )^{4}$ & Compound name & $\mathrm{T} 1$ & $\mathrm{~T} 2$ & T3 & Control & $P$ \\
\hline MUFA & 25.03 & (Z)-9octadecenoic acid & $17.48 \pm 15.16$ & $15.32 \pm 12.80$ & $2.77 \pm 0.23$ & $8.56 \pm 5.35$ & 0.935 \\
\hline SFA & 25.03 & butanoic acid & $0.36 \pm 0.29$ & $0.36 \pm 0.21$ & $0.10 \pm 0.00$ & $0.11 \pm 0.03$ & 0.320 \\
\hline SFA & 18.92 & dodecanoic acid & $0.31 \pm 0.19$ & $0.19 \pm 0.09$ & $0.10 \pm 0.01$ & $0.14 \pm 0.05$ & 0.435 \\
\hline SFA & 27.00 & eicosanoic acid & $4.78 \pm 3.85$ & $6.08 \pm 4.69$ & $0.92 \pm 0.17$ & $2.58 \pm 1.69$ & 0.569 \\
\hline SFA & 24.31 & heptadecanoic acid & $0.15 \pm 0.11$ & $0.05 \pm 0.02$ & $0.04 \pm 0.01$ & $0.06 \pm 0.02$ & 0.621 \\
\hline SFA & 23.35 & hexadecanoic acid & $191.67 \pm 113.36$ & $93.67 \pm 24.87$ & $82.04 \pm 8.34$ & $100.87 \pm 28.59$ & 0.692 \\
\hline SFA & 26.15 & nonadecanoic acid & $0.01 \pm 0.01$ & $0.00 \pm 0.00$ & $0.00 \pm 0.00$ & $0.00 \pm 0.00$ & 0.692 \\
\hline SFA & 25.77 & octadecanoic acid & $195.96 \pm 129.12$ & $92.99 \pm 32.14$ & $74.53 \pm 7.37$ & $104.56 \pm 35.19$ & 0.764 \\
\hline SFA & 22.32 & pentadecanoic acid & $0.10 \pm 0.08$ & $0.05 \pm 0.03$ & $0.02 \pm 0.00$ & $0.04 \pm 0.01$ & 0.544 \\
\hline SFA & 21.24 & tetradecanoic acid & $16.12 \pm 10.29$ & $8.51 \pm 6.32$ & $5.37 \pm 0.62$ & $6.85 \pm 2.19$ & 0.634 \\
\hline \multirow[t]{2}{*}{$\sum S F A$} & & & $23.91 \pm 9.28$ & $45.50 \pm 23.77$ & $22.43 \pm 8.38$ & $18.13 \pm 6.41$ & 0.814 \\
\hline & 35 & Cholesterol & $274.76 \pm 229.45$ & $58.99 \pm 19.40$ & $88.93 \pm 18.36$ & $88.28 \pm 8.62$ & 0.647 \\
\hline
\end{tabular}

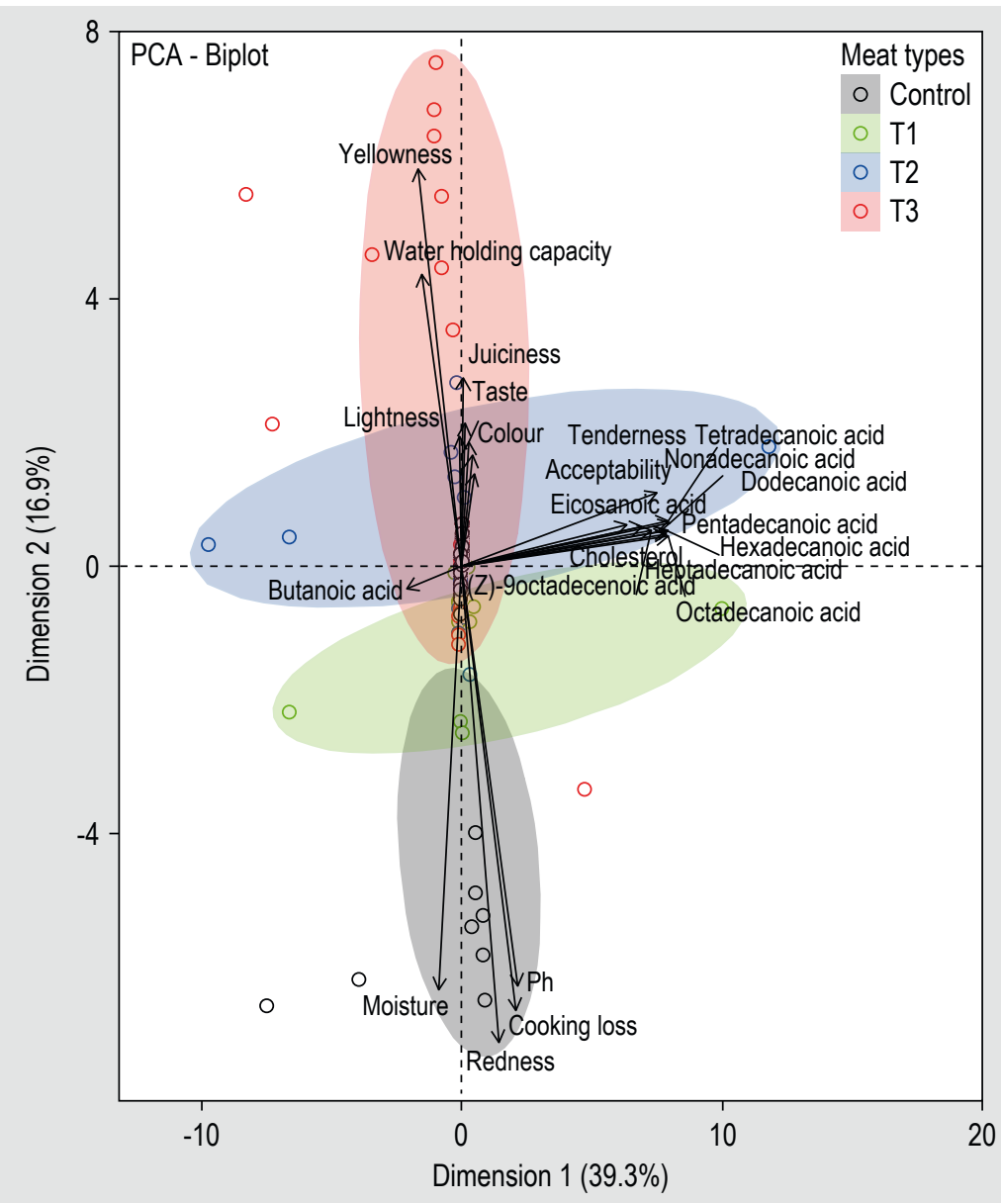

Figure 3. PCA showing the connection between sensory and physicochemical attributes. Control = conventional feed, $\mathrm{T} 1=\mathbf{2 5} \%$ D. intortum $+75 \%$ BSFLM, T2 = 50\% D. intortum $+50 \%$ BSFLM, T3 = 75\% D. intortum $+25 \%$ BSFLM. 
hypertrophy of muscles in broilers, especially the breast (Popova et al., 2020). Studies on broiler meat quality report different values for the $\mathrm{pH}$ in breast meat. Although the $\mathrm{pH}$ was affected by the inclusion of various proportions of $D$. intortum-BSFLM in the diet, values were within the normal range. However, $\mathrm{pH}$ values were significantly lower in the group consuming $D$. intortum-BSFLM meals. This could be explained by the fact that BSFL are rich in lauric acid, which increases fatty acid levels (Cullere et al., 2016, 2019; Zeiger et al., 2017). We do not have any record of the effect of $D$. intortum on poultry meat acidity, but our results suggest that its inclusion tend to lower the $\mathrm{pH}$ values in the broilers meat.

Our study also demonstrated a direct relationship between $\mathrm{pH}$ values, the water holding capacity and meat colour. The visual appearance in terms of colour is affected by dietary inclusion, which could impact consumers' choices. No significant differences were found in meat lightness; however, the higher the $D$. intortum content in the diet, the higher the yellowness and the lower the redness. Our results are in line with Cullere et al. (2016), who reported a dose-dependent effect of BSF defatted meal on the redness index of quail breast with a decrease of its values in the birds consumed higher content of the meal. The increased yellowness could be explained by the increase in beta-carotene or other pigments such as chlorophyll and xanthophyll present in $D$. intortum (Smith et al., 2002). Our results are in agreement with İpçak and Alçiçek (2018), who reported that adding Capsicum oleoresin, carvacrol, cinnamaldehyde and their mixtures in broiler diets improved the sensory, physical and chemical properties of breast and leg meat. Capsicum oleoresin, carvacrol, cinnamaldehyde and their mixtures contain certain functional compounds and desirable pigments (carotenoids, tocopherols, capsaicinoids (capsacicin) also found in D. intortum. Compounds such as antioxidants, polyphenols, flavonoids, anthocyanins and xanthophylls could have played a role in the improved meat quality attributes as pointed by İpçak and Alçiçek (2018).

Dietary fatty acid composition is critical in determining the fatty acid profile of broiler meat (Rymer and Givens, 2005; Schiavone et al., 2007, 2010). The inclusion of BSFLM and $D$. intortum influenced the fatty acid profile of the meat. The increase in MUFA and SFA could be ascribed to the fact that BSF meals contain a significant amount of lauric acid, as previously suggested (Cullere et al., 2019; Popova et al., 2020; Schiavone et al., 2017, 2019).

Fat content also affects the palatability and flavour of the meat to a great extent, and small proportions of oxidised fatty acids such as those found in the BSFL could have significantly altered the flavour of the meat (Belitz et al., 2009; Min and Ahn, 2014).
We did not detect polyunsaturated fatty acids PUFAs in any of the treatments; however, BSFLM are known to be relatively scarce in PUFAs (Ewald et al., 2019). De Souza Villela et al., (2021) reported that an increase use of dietary BSFLM at $20 \%$ led to a significant decrease by $37.4 \%$ in a total quantity of PUFAs. However in our study we used higher rates of BSFLM (75\%, 50\% and 25\% BSFLM). The cholesterol levels in T1 was particularly high (75\%BSFLM:25\%DI) and relatively low in other treatments. Our results support previous studies which demonstrated that inclusion of legumes and forages in broiler bird diets reduce cholesterol concentration in the animals' blood and meat, through improved feed conversion efficiency and improved digestion and metabolism (Jiang et al., 2012; Krauze and Grela, 2010; Ponte et al., 2005; Purwin et al., 2014). Higher lipid content implies higher risks of cardiovascular diseases (Schaefer, 2002). Our results therefore suggest that meats from T3 $(75 \% D$. intortum $+25 \%$ BSFLM) may have additional health benefits.

\section{Conclusion and recommendations}

The current study shows that the inclusion of $D$. intortum and BSFLM in poultry diets affects the sensory and physicochemical qualities of the meat. The PCA analysis indicated that overall, the tested meats were distinct in their sensory and physicochemical properties. T3 and control meats were divergent, whereas T1 and T2 were at the interface between the two. The variations in physicochemical properties may account for the difference in organoleptic perception for meat from chicken feed with $D$. intortum-BSFLM, especially T3, which could be compared to free-range chicken 'kienyeji', usually more preferred due to its perceived superior taste (Omondi, 2017). Further research should focus on feed modulation in relation to consumers' preference and potential health benefits.

\section{Acknowledgements}

Financial support for this research was provided by the Push-Pull for Sub-Saharan Africa Project funded by Biovision Foundation, Switzerland. The authors of this study also acknowledge support from the Netherlands Organization for Scientific Research, WOTRO Science for Global Development (NWO-WOTRO) (ILIPA - W 08.250.202), the Canadian International Development Research Centre (IDRC), and the Australian Centre for International Agricultural Research (ACIAR) (INSFEED - Phase 2: Cultivate Grant No. 108866-001) and the Rockefeller Foundation (SiPFeed - Grant No. 2018 FOD 009) through the International Centre of Insect Physiology and Ecology (icipe).

We also gratefully acknowledge the icipe core funding provided by DFCO of the United Kingdom, the Swedish International Development Cooperation Agency (SIDA), 
the Swiss Agency for Development and Cooperation (SDC), the Federal Ministry for Economic Cooperation and Development (BMZ), Germany, and the Kenyan Government. However, the views expressed herein do not necessarily reflect the official opinions of the donors.

The authors gratefully acknowledge Isaiah E. Rachami, Faith Wamurango Nyamu, Shem Ondiaka, Joshua M. Wambua, Claudia Munuhe, and Diana Kemunto for their technical support in the laboratory and for providing dried black soldier fly larvae produced at icipe.

\section{Conflict of interest}

The authors declare no conflict of interest. The funders had no role in the design of the study, in the collection, analyses, or interpretation of data, in the writing of the manuscript, or in the decision to publish the results.

\section{References}

Abdullah, N.S., 1974. The nutritive value of some Kenya feedstuffs and the effect of protein and energy rich concentrate supplementation on the utilization of Chloris gayana tray by wether sheep. PhD-thesis, Department of Food Science, Nutrition and Technology, University of Nairobi, Nairobi, 286 pp.

Albrecht, A., Hebel, M., Mittler, M., Hurck, C., Kustwan, K., Heitkönig, B., Bitschinski, D., Kreyenschmidt, J. and Lobato, L., 2019. Influence of different production systems on the quality and shelflife of poultry meat: a case study in the German sector. Journal of Food Quality, Article ID: 3718057. https://doi.org/10.1155/2019/3718057

Alex, S., Varela, M. and Gonc, A.A., 2017. Quality characteristics of broiler chicken meat from free-range and industrial poultry system for the consumers. Journal of Food Science and Technology 54: 1818-1826. https://doi.org/10.1007/s13197-017-2612-x

Almeida, J.C., Perassolo, M.S., Camargo, J.L., Bragagnolo, N. and Gross, J.L., 2006. Fatty acid composition and cholesterol content of beef and chicken meat in Southern Brazil. Revista Brasileira de Ciências Farmacêuticas 42(1): 109-117. https://doi.org/10.1590/ S1516-93322006000100012

Association of Official Analytical Chemists (AOAC), 1990. Official methods of analysis of the Association of Analytical Chemists International. Association of Official Analytical Chemists, Gaithersburg, MD, USA.

Association of Official Analytical Chemists (AOAC), 2002. Official methods of analysis of the Association of Analytical Chemists International. Association of Official Analytical Chemists, Gaithersburg, MD, USA.

Belitz, H.D., Grosch, W. and Schieberle, P., 2009. Food chemistry. In Belitz, H.D., Grosch, W. and Schieberle, P. (eds.) Meat, $4^{\text {th }}$ edition. Vol. 12. Springer-Verlag, Berlin, Germany, pp. 605-608.

Bett, H.K., Musyoka, M.P., Peters, K.J. and Bokelmann, W., 2012. Demand for meat in the rural and urban areas of Kenya: a focus on the indigenous chicken. Economics Research International, Article ID: 401472. https://doi.org/10.1155/2012/401472
Christie, W.W., 1993. Preparation of ester derivatives of fatty acids for chromatographic analysis. Advances in Lipid Methodology 2: 69-111.

Cullere, M., Tasoniero, G., Giaccone, V., Acuti, G., Marangon, A. and Zotte, A.D., 2017. Black soldier fly as dietary protein source for broiler quails: meat proximate composition, fatty acid and amino acid profile, oxidative status and sensory traits. Animal 12(3): 640647. https://doi.org/10.1017/S1751731117001860

Cullere, M., Tasoniero, G., Giaccone, V., Claeys, E., De Smet, S. and Zotte, A.D., 2016. Black soldier fly as dietary protein source for broiler quails: apparent digestibility, excreta microbial load, feed choice, performance, carcass and meat traits. Animal 10(12): 19231930. https://doi.org/10.1017/S1751731116001270

Cullere, M., Woods, M.J., Van Emmenes, L., Pieterse, E., Hoffman, L.C. and Dalle Zotte, A., 2019a. Hermetia illucens larvae reared on different substrates in broiler quail diets: effect on physicochemical and sensory quality of the quail meat. Animals 9: 525. https://doi. org/10.3390/ani9080525

Cullere, M.G.T., Giaccone, V., Acuti, G., Marangon, A. and Dalle Zotte, A., 2018. Black soldier fly as dietary protein source for broiler quails: meat proximate composition, fatty acid and amino acid profile, oxidative status and sensory traits. Animal 12(3): 640-647. https:// doi.org/10.1017/S1751731117001860

Dabbou, S., Gai, F., Biasato, I., Capucchio, M.T., Biasibetti, E., Dezzutto, D., Meneguz, M., Plachà, I., Gasco, L. and Schiavone, A., 2018. Black soldier fly defatted meal as a dietary protein source for broiler chickens: effects on growth performance, blood traits, gut morphology and histological features. Journal of Animal Science and Biotechnology 9: 49. https://doi.org/10.1186/s40104-018-0266-9

Damaziak, K., Stelmasiak, A., Riedel, J., Zdanowska-Sasiadek, Z., Bucfaw, M., Gozdowski, D. and Michalczuk, M., 2019. Sensory evaluation of poultry meat: a comparative survey of results from normal sighted and blind people. PLoS ONE 14(1): e0210722. https://doi.org/10.1371/journal.pone.0210722

De Mendiburu, F., 2020. Agricolae: statistical procedures for agricultural research. R package version 1.3-3. Available at: https:// CRAN.R-project.org/package $=$ agricolae

de Souza Vilela, J., Alvarenga, T.I.R.C., Andrew, N.R., McPhee, M., Kolakshyapati, M., Hopkins, D.L. and Ruhnke, I., 2021. Technological quality, amino acid and fatty acid profile of broiler meat enhanced by dietary inclusion of black soldier fly larvae. Foods 10: 297. https:// doi.org/10.3390/foods10020297

Ewald, N., Vidakovic, A., Langeland, M., Kiessling, A., Samples, S. and Lalander, C., 2019. Fatty composition of black soldier fly larvae (Hermetia illucens) - possibilities and limitations for modification through diet. Waste Management 102: 40-47. https://doi. org/10.1016/j.wasman.2019.10.014

Federation of Animal Science Societies (FASS), 2010. Guide for the care and use of agricultural animals in research and teaching. FASS, Champaign, IL, USA.

Gariglio, M., Dabbou, S., Biasato, I., Capucchio, M.T., Colombino, E., Hernández, F., Madrid, J., Martínez, S., Gai, F., Caimi, C., Oddon, S.B., Meneguz, M., Trocino, A., Vincenzi, R., Gasco, L. and Schiavone, A., 2019. Nutritional effects of the dietary inclusion of partially defatted Hermetia illucens larva meal in Muscovy duck. Journal of Animal Science and Biotechnology 10: 37. 
Gross, W.B. and Siegel, H.S., 1983. Evaluation of the Heterophil/ Lymphocyte ratio as a measure of stress in chickens. Avian Diseases 27(4): 972-979.

Heinritz, S.N., Hoedtke, S., Martens, S.D., Peters, M. and Zeyner, A., 2012. Evaluation of ten tropical legume forages for their potential as pig feed supplement. Livestock Research for Rural Development 24(1). http://www.lrrd.org/lrrd24/1/hein24007.htm

İpçak, H.H. and Alçiçek, A., 2018. Addition of Capsicum oleoresin, Carvacrol, Cinnamaldehyde and their mixtures to the broiler diet II : effects on meat quality. Science and Technology 60: 9. https:// doi.org/10.1186/s40781-018-0165-9

Jiang, J.F., Song, X.M., Huang, X., Zhou, W.D., Wu, J.L., Zhu, Z.G., Zheng, H.C. and Jiang, Y.Q., 2012. Effects of Alfalfa meal on growth performance and gastrointestinal tract development of growing ducks. Asian-Australasian Journal of Animal Science 25(10): 14451450. https://doi.org/10.5713/ajas.2012.12190

Kassambara, A. and Mundt, F., 2020. Factoextra: extract and visualize the results of multivariate data analyses. R-package version 1.0.7. Available at: https://CRAN.R-project.org/package=factoextra

Krauze, M. and Grela, E.R., 2010. Effects of an alfalfa concentrate in turkey diets on performance and some blood parameters. Archiv Fur Geflugelkunde 74: 226-232. https://doi.org/10.1016/j.psj.2019.11.030

Lê, S., Josse, J. and Husson, F., 2008. FactoMineR: an R package for multivariate analysis. Journal of Statistical Software 25(1): 1-18.

Lichovníková, M., Jandásek, J., Jůzl, M. and Dračková, E., 2009. The meat quality of layer males from free range in comparison with fast growing chickens. Czech Journal of Animal Science 54(11): 490-497. https://doi.org/10.17221/3/2009-CJAS

Liland, N.S., Biancarosa, I., Araujo, P., Biemans, D., Bruckner, C.G., Waagb, R., Torstensen, B.E. and Lock, E., 2017. Larvae by feeding seaweed-enriched media modulation of nutrient composition of black soldier fly (Hermetia illucens) larvae by feeding seaweedenriched media. PLoS ONE 12(8): e0183188. https://doi. org/10.1371/journal.pone.0183188

Lonergan, S.M., Deeb, N., Fedler, C.A. and Lamont, S.J., 2004. Breast meat quality and composition in unique chicken populations. Poultry Science 82(12): 1990-1994. https://doi.org/10.1093/ps/82.12.1990

Makkar, H.P.S., Tran, G., Heuzé, V. and Ankers, P., 2014. State-of-the-art on use of insects as animal feed. Animal Feed Science and Technology 197: 1-33. https://doi.org/10.1016/j.anifeedsci.2014.07.008

McGlone, J.J., 2001. Farm animal welfare in the context of other society issues: toward sustainable systems. Livestock Production Science 72: $75-81$

Min, B. and Ahn, D.U., 2014. Mechanism of lipid peroxidation in meat and meat products - a review. Food Science and Biotechnology 14(1): 152-163. https://doi.org/10.31274/rtd-180813-13142

Mmereole, F.U.C., 2008. Effects of replacing ground nut cake with rubber seed meal on the haematological and serological indices of broilers. International Journal of Poultry Science 7(6): 622-624. https://doi.org/10.3923/ijps.2008.622.624

Mutisya, M.M., Agbodzavu, M.K., Kinyuru, J.N., Tanga, C.M., Gicheha, M., Hailu, G., Salifu, D., Khan, Z. and Niassy, S., 2021. Can black soldier fly Desmodium intortum larvae-based diets enhance the performance of Cobb500 broiler chickens and smallholder farmers' profit in Kenya? Poultry Science 100(2): 420-430. https://doi. org/10.1016/j.psj.2020.11.021
National Research Council (NRC), 1994. Nutrient requirement of poultry. $9^{\text {th }}$ revised ed. National Academic Press. Washington, DC, USA.

Omondi, D.J., 2017. The influence of strategies in sustaining agribusiness: a case of poultry farmers in Kasarani, Nairobi. United States International University - Africa. Available at: http://erepo. usiu.ac.ke/11732/3413

Ondulla, T.T., Livingston, M.L., Wall, B., Sanders, E.T., VuThien, C., Malheiros, R.D., Livingston, K.A., Carvalho, L.V. and Ferket, P.R., 2019. Meat quality and sensory attributes of meat produced from broiler chickens fed a high oleic peanut diet. Poultry Science 98(10): 5188-5197. https://doi.org/10.3382/ps/pez258

Ponte, P.I.P., Mendes, I., Quaresma, M., Aguiar, M.N.M., Lemos, J.P.C., Ferreira, L.M.A., Soares, M.A.C., Alfaia, C.M., Prates, J.A.M. and Fontes, C.M.G.A., 2005. Cholesterol levels and sensory characteristics of meat from broilers consuming moderate to high levels of alfalfa. Poultry Science 83(5): 810-814. https://doi. org/10.1093/ps/83.5.810

Popova, T., Petkov, E. and Ignatova, M., 2020. Effect of black soldier fly (Hermetia illucens) meals on the meat quality in broilers. Agricultural and Food Science 29: 177-188. https://doi.org/10.23986/ afsci.88098

Purwin, C., Fijałkowska, M., Pysera, B., Lipiński, K., Sienkiewicz, S., Piwczyński, D. and Puzio, N., 2014. Nitrogen fractions and amino acid content in alfalfa and red clover immediately after cutting and after wilting in the field. Journal of Elementology 3: 723-734. https://doi.org/10.5601/jelem.2014.19.2.692

Qiao, M., Fletcher, D.L., Smith, D.P. and Northcutt, J.K., 2001. The effect of broiler breast meat color on $\mathrm{pH}$, moisture, water-holding capacity, and emulsification capacity. Poultry Science 80(5): 676680. https://doi.org/10.1093/ps/80.5.676

R Core Team, 2020. R: a language and environment for statistical computing. R Foundation for Statistical Computing, Vienna, Austria. Available at: https://www.R-project.org/.

Ravindran, V., 2013. Poultry feed availability and nutrition in developing countries: main ingredients used in poultry feed formulation. Poultry Development Review 2(10): 694-695.

Reicks, A.L., Brooks, J.C., Garmyn, A.J., Thompson, L.D., Lyford, C.L. and Miller, M.F., 2011. Demographics and beef preferences affect consumer motivation for purchasing fresh beef steaks and roasts. Meat Science 87: 403-411. https://doi.org/10.1016/j.meatsci.2010.11.018

Rymer, C. and Givens, D.I., 2005. n-3 fatty acid enrichment of edible tissue of poultry: a review. Lipids 40(2): 121-130. https://doi. org/10.1007/s11745-005-1366-4

Santos-Silva, J. and Vaz Portugal, A., 2001. The effect of weight on carcass and meat quality of Serra da Estrela and Merino Branco lambs fattened with dehydrated lucerne. Animal Research 50: 289298. https://doi.org/10.1051/animres:2001132

Schaefer, E.J., 2002. Lipoproteins, nutrition and heart disease. The American Journal of Clinical Nutrition 75(2): 191-212. https://doi. org/10.1093/ajcn/75.2.191

Schiavone, A., Chiarini, R., Marzoni, M., Castillo, A., Tassone, S. and Romboli, I., 2007. Breast meat traits of Muscovy ducks fed on a microalga (Crypthecodinium cohnii) meal supplemented diet. British Poultry Science 48(5): 573-579. https://doi. org/10.1080/00071660701615796 
Schiavone, A., Cullere, M., De Marco, M., Meneguz, M., Biasato, I., Bergagna, S., Dezzutto, D., Gai, F., Dabbou, S., Gasco, L. and Dalle Zotte, A., 2017. Partial or total replacement of soybean oil by black soldier larvae (Hermetia illucens L.) fat in broiler diets: effect on growth performances, feed-choice, blood traits, carcass characteristics and meat quality. Italian Journal of Animal Science 16: 93-100. https://doi.org/10.1080/1828051X.2016.1249968

Schiavone, A., Dabbou, S., Petracci, M., Zampiga, M., Sirri, F., Biasato, I., Gai, F. and Gasco, L., 2019. Black soldier fly defatted meal as a dietary protein source for broiler chickens: effects on carcass traits, breast meat quality and safety. Animal 13: 2397-2405. https://doi. org/10.1017/S1751731119000685

Schiavone, A., Marzoni, M., Castillo, A.J., Neryand Romboli, I., 2010. Dietary lipid sources and vitamin E affect fatty acid composition or lipid stability of breast meat from Muscovy duck. Canadian Journal of Animal Science 90(3): 371-378. https://doi.org/10.4141/ CJAS10010

Secci, G., Moniello, G., Gasco, L., Bovera, F. and Parisi, G., 2018. Barbary partridge meat quality as affected by Hermetia illucens and Tenebrio molitor larva meals in feeds. Food Research International 112: 291-298. https://doi.org/10.1016/j.foodres.2018.06.045

Smith, D.P., Lyon, C.E. and Lyon, B.G., 2002. The effect of age, dietary carbohydrate source, and feed withdrawal on broiler breast fillet color. Poultry Science 81(10): 1584-1588. https://doi.org/10.1093/ ps/81.10.1584
Sow, T.M.A. and Grongnet, J.F., 2010. Sensory characteristics and consumer preference for chicken meat in Guinea. Poultry Science 89(10): 2281-2292. https://doi.org/10.3382/ps.2010-00679

Teguia, A. and A. Beynen. 2005. Alternative feedstuffs for broilers in Cameroon. Journal of Agricultural Extension and Rural Development 17(3). Available at: http://www.lrrd.org/lrrd17/3/ tegu17034.htm

Van der Poel, A.F.B., Van Krimpen, M.M., Veldkamp, T. and Kwakkel, R.P., 2013. Unconventional protein sources for poultry feeding opportunities and threats. Proceedings of the $19^{\text {th }}$ Symposium on Poultry Nutrition. 26-29 August 2013. Potsdam, Germany, pp. 14-24.

Wideman, N., O'Bryan, C. and Crandall, P., 2016. Factors affecting poultry meat colour and consumer preferences - a review. World's Poultry Science Journal 72(2): 353-366. https://doi.org/10.1017/ S0043933916000015

Zeiger, K., Popp, J., Becker, A., Hankel, J., Visscher, C., Klein, G. and Meemken, D., 2017. Lauric acid as feed additive - an approach to reducing Campylobacter spp. in broiler meat. PLoS ONE 12(4): e0175693. https://doi.org/10.1371/journal.pone.0175693

Zhao, T., Luo, H., Zhang, Y., Liu, K., Jia, H., Chang, Y. and Jiao, L., 2013. Effect of vitamin E supplementation on growth performance, carcass characteristics and intramuscular fatty acid composition of Longissimus dorsi muscle in 'Tan' sheep. Chilean Journal of Agricultural Research 73: 358-365. https://doi.org/10.4067/S071858392013000400005 
